\title{
UCRL-TR-235948
}

LAWRENCE LIVERMORE N A T IO N A L LABORATORY

S. Bajt

October 30, 2007

\section{LCLS soft x-ray imager mirrors and their performance}


This document was prepared as an account of work sponsored by an agency of the United States government. Neither the United States government nor Lawrence Livermore National Security, LLC, nor any of their employees makes any warranty, expressed or implied, or assumes any legal liability or responsibility for the accuracy, completeness, or usefulness of any information, apparatus, product, or process disclosed, or represents that its use would not infringe privately owned rights. Reference herein to any specific commercial product, process, or service by trade name, trademark, manufacturer, or otherwise does not necessarily constitute or imply its endorsement, recommendation, or favoring by the United States government or Lawrence Livermore National Security, LLC. The views and opinions of authors expressed herein do not necessarily state or reflect those of the United States government or Lawrence Livermore National Security, LLC, and shall not be used for advertising or product endorsement purposes.

This work performed under the auspices of the U.S. Department of Energy by Lawrence Livermore National Laboratory under Contract DE-AC52-07NA27344. 


\title{
LCLS soft $x$-ray imager mirrors and their performance
}

\author{
Saša Bajt \\ Lawrence Livermore National Laboratory \\ October 19, 2007
}

Soft X-ray imager mirrors have been designed, calibrated and fabricated at Lawerence Livermore National Laboratory and characterized at the Advanced Light Source for their performance between 200 and $1300 \mathrm{eV}$.

The mirrors are coated with a multilayer coating consisting of 70 bilayers of $\mathrm{W} / \mathrm{SiC}$. The mirrors are to reflect at $22.5 \mathrm{deg}$ from grazing angle at $1.50 \mathrm{~nm}$ wavelength and the width of the reflectivity peak should be at least $1.3 \%$. Also, the mirrors should be non-reflective elsewhere. Our multilayer design was optimized to satisfy these requirements. The coating is very challenging since the individual layer thicknesses need to be less than 1 $\mathrm{nm}$ thick and reproducibility from layer to layer is crucial. To minimize the second harmonic peak we designed a multilayer with $\Gamma=0.5$ (W and $\mathrm{SiC}$ layer thicknesses are the same). This way we end up with a mirror that has only the $1^{\text {st }}$ and $3^{\text {rd }}$ harmonic peak as shown in Figure 1. To suppress reflectivity outside the first peak we used our novel approach, an antireflective coating. Modeling predicted substantial reduction in reflectivity, especially for lower energies as shown in Figure 1.

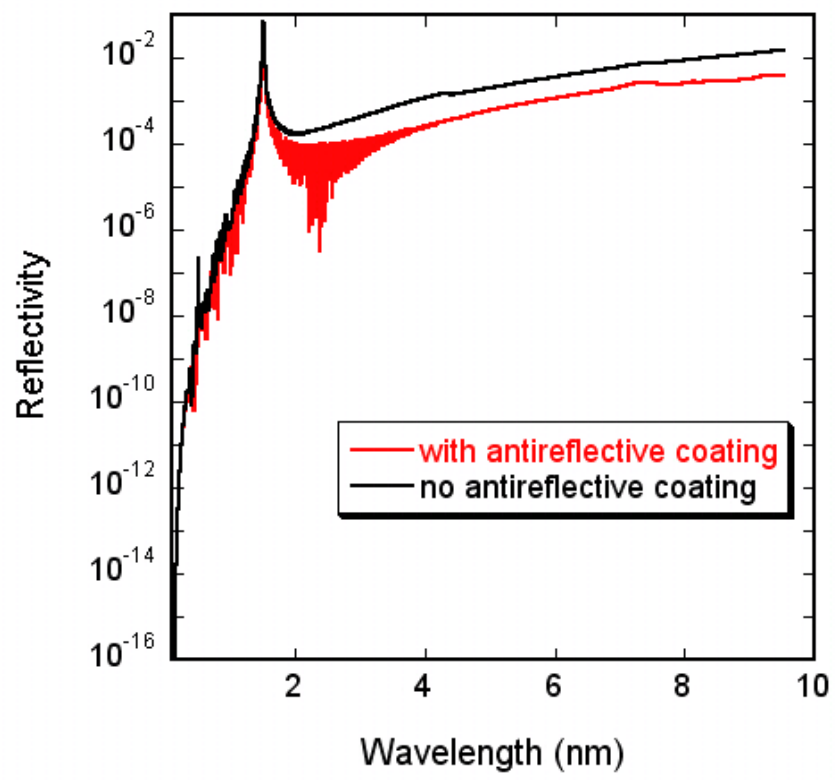

Figure 1: Modeled reflectivity shows complete suppression of the $2^{\text {nd }}$ order harmonic peak at $0.76 \mathrm{~nm}$ and a very weak $3^{\text {rd }}$ harmonic peak at $0.5 \mathrm{~nm}\left(10^{-7}\right)$ as an effect of the antireflective coating. The red curve is a mirror with antireflective coating and the black is the one without. 
The experimental results of the soft x-ray imager mirror as measured at the ALS are shown in Figure 2 (log and linear scale). The energy range over which we measured the reflectivity is limited by the beamline hardware. This plot is a compilation of about six scans over different energy ranges using different gratings, filters and order sorter positions. The measured reflectivity of the peak at $1.505 \mathrm{~nm}$ is $4.3 \%$ with the peak width of $0.028 \mathrm{~nm}$ or $1.8 \%$, satisfying the specs on the peak width.
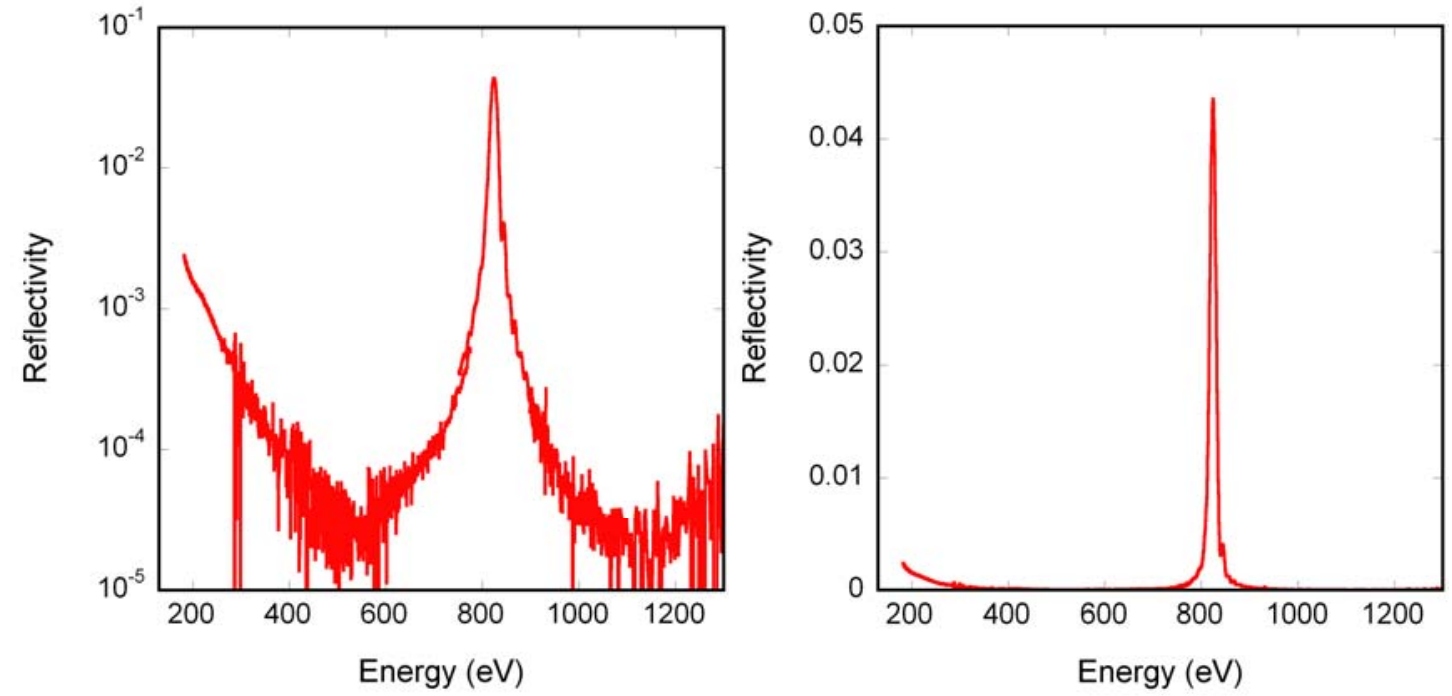

Figure 2: Measured reflectivity of the soft X-ray imager mirror for the LCLS between 200 and $1300 \mathrm{eV}$ on a logarithmic (left) and linear (right) scale.

The other important specification was overall low reflectivity (except for $1^{\text {st }}$ harmonic). We demonstrated this with the antireflective coating that is applied on these mirrors. The application of the antireflective coating also reduces the reflectivity of the $1^{\text {st }}$ harmonic peak from $8.23 \%$ to $4.30 \%$, which is in agreement with our modeling results. As shown in Figure 3 the antireflective coating substantially suppresses reflectivity in the energy range between 200 and $800 \mathrm{eV}$. 

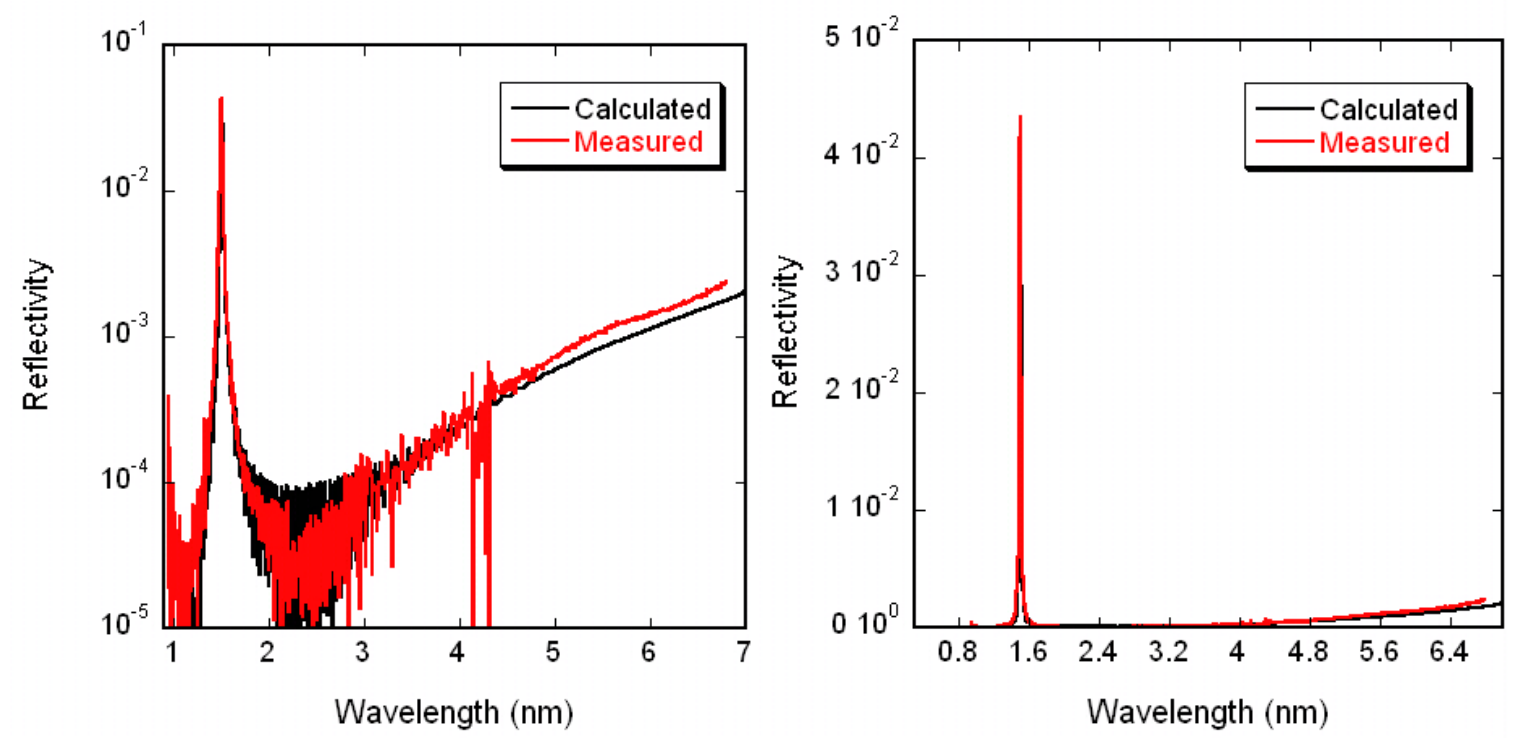

Figure 3: Measured (red) and calculated (black) reflectivity of soft x-ray imager mirror for the LCLS on a logarithmic (left) and liner (right) scale.

Considering the excellent agreement between modeled and measured data we then take a step further and extrapolate the calculation (Figure 1) up to $10 \mathrm{keV}(0.12 \mathrm{~nm})$. It is clear that the $2^{\text {nd }}$ order harmonic is suppressed while the $3^{\text {rd }}$ harmonic has reflectivity of only $10^{-7}$. Finally, we also calculate the rocking curve of the $1^{\text {st }}$ harmonic (Figure 4), which is of importance if a two bounce mirror system will be necessary.

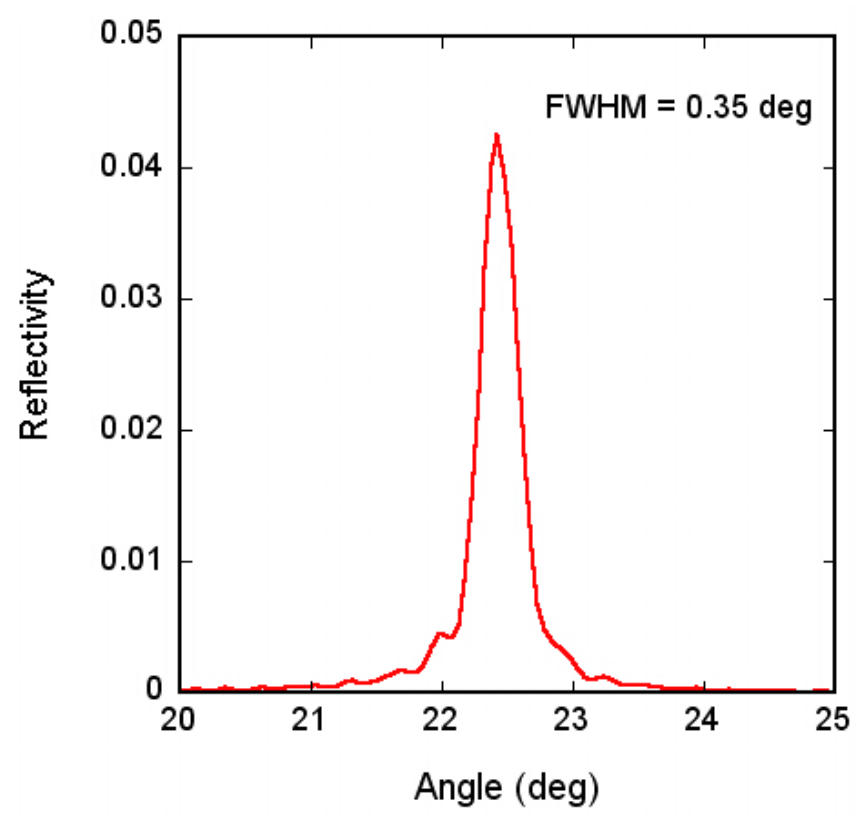

Figure 4: Calculated rocking curve for the $1^{\text {st }}$ harmonic. 
In summary, two $100 \mathrm{~mm}$ mirrors with $>4 \%$ reflectivity at $1.50 \mathrm{~nm}$ and $1.8 \%$ FWHM for operation at $22.5 \mathrm{deg}$ grazing angle were fabricated. Both mirrors are coated with antireflective coating that suppresses radiation outside the $1^{\text {st }}$ harmonic. Experimental and modeling results are in excellent agreement indicating that we understand the physics of this multilayer system very well.

This work was performed under the auspices of the U.S. Department of Energy by Lawrence Livermore National Laboratory under Contract DE-AC52-07NA27344. 